\title{
ESCRIBIR UNA HISTORIA SOCIAL DE LA LITERATURA LATINOAMERICANA
}

Sobre Adolfo Prieto. Conocimiento de la Argentina. Estudios literarios reunidos. Selección y Prólogo de Nora Avaro. Rosario: Editorial Municipal de Rosario, 2015. 563 pp.

Nora Avaro nos cuenta en su notable prólogo a esta antología que Conocimiento de la Argentina fue un proyecto de la Editorial Vigil hacia fines de la década del 60. Consistía en una colección de fascículos dirigida por Adolfo Prieto y tenía como objetivo "poner el libro ahî", ya que en su origen estaba la idea de que este conocimiento de la Argentina podía alcanzarse a partir de la publicación de veinticuatro textos divididos en dos secciones amplias "La Argentina histórica" y "La Argentina Contemporánea”. La primera parte a su vez se dividía en dos secciones: "Interpretaciones y comentarios", que se proponía la reedición de textos que se entendían claves para la interpretación nacional y "Testimonios", sección en la que se proyectaba editar una selección de escritos autobiográficos. En "La Argentina Contemporánea", se preveía una colección con colaboraciones para la escritura de estudios crítico sociológicos que explicaran la compleja problemática de las distintas "expresiones culturales".

Este plan es retomado por Nora Avaro a la hora de diseñar un orden para esta reunión de textos que recorre la totalidad de la obra crítica de Adolfo Prieto, una obra que se extiende a lo largo de sesenta años. Un orden que si bien recupera la 
dimensión cronológica, esa voluntad de "hacer una historia de la literatura latinoamericana", construye fundamentalmente una trama de problemas e inquietudes que la muy pertinente selección (es de destacar el trabajo recopilatorio que recupera textos dispersos y de naturaleza muy variada: prólogos, ensayos, artículos, entrevistas) y ubicación de los textos (que no responde a las fechas de publicación) traduce en un índice de series amplias que ponen de manifiesto una voluntad crítica totalizante.

El recorrido comienza con una suerte de introducción, "El Paraná y su expresión literaria" (1973). Siguiendo los avatares de las representaciones literarias del Paraná desde sus orígenes virreinales hasta las formas contemporáneas, Prieto elabora una historia posible para la literatura argentina. En esta historia que fluye al ritmo de las metáforas del río, construye una panorámica que incluye todos los registros (géneros, tonos, estéticas) del paisaje como cifra. Cifra que se modula en la intersección del imperativo estético, la urgencia política y una experiencia poética del mundo.

Las Memorias de la Revolución es el título de la sección inicial. Dos textos aparecen en este primer momento: "Los años de la emancipación política" (1974) y "El impacto de Mayo en la literatura autobiográfica" (1960). En ambos textos Prieto aborda el estudio de los géneros de la intimidad (objeto privilegiado en este momento de su producción) pensándolos como espacios en los que se cruza el registro de la Historia y la inscripción subjetiva de la historia. Así, memorias y diarios, le sirven principalmente como documentos que atestiguan de qué manera los cambios revolucionarios, vividos por sus protagonistas como radicales, generan una escritura teñida por la incertidumbre política y el temor al fracaso. La escritura se construye y se tensiona en la necesidad de un posicionamiento político generando un juego de perspectivas que invade $y$ 
trastoca las pretensiones de objetividad y de registro espontáneo que subyacen a las motivaciones constructivas de los textos. Aquellas escrituras íntimas posteriores al proceso revolucionario, marcadas por las tensiones facciosas, permiten andar la trama textual que se teje en la intersección de la historia política personal y el juicio de la opinión pública. La incipiente democratización pone en jaque las jerarquías coloniales, ante la crisis estos escritores intentan posicionarse oscilando entre la asunción desgarrada del conflicto y la negación del mismo. Para Prieto, Sarmiento representa, por la encarnación de su escritura, la condensación de estas dominantes de una manera prístina y particularmente problemática.

Continuando en esta zona, la segunda sección es la del Episodio rosista. Tres textos componen este segundo momento: "Las guerras civiles. El rosismo" (1974), "El rosismo. La reorganización nacional" (1974) y el amplio estudio "Proyección del rosismo en la literatura argentina" (1962). Continuando la lectura de escritos autobiográficos, Prieto piensa de qué manera aparece y se intenta explicar el fenómeno del gobierno rosista en el contexto de las luchas facciosas posteriores a los primeros intentos de gobierno post revolucionarios. En el marco de las disputas entre unitarios y federales la figura de Rosas condensa, como el gran caudillo al poder, las dominantes simbólicas y culturales de este proceso, volviéndose un emblema. Un emblema que se dibuja en la construcción pasional de su figura y en la explicación de los elementos en conflicto que lo constituyeron en el personero del poder. En el mismo sentido, las memorias escritas después de Caseros dan cuenta de la instauración de una ideología dominante que impuso la demonización de la figura de Rosas como una forma de autojustificación para la acción política de los distintos autores. Prieto rastrea esta matriz ideológica y explicativa pendular (rosismo - antirosismo) hasta su paulatina 
clausura en las últimas décadas del siglo XIX con la aparición de un nuevo enemigo aglutinante: el inmigrante. Siempre teniendo en cuenta como marco el proceso de modernización política de la Argentina.

En la tercera sección que esta antología nos propone aparece el primer nombre propio: Sarmiento. Esta serie está compuesta por un conjunto de textos de variada naturaleza, publicados en etapas muy distintas, dejando de manifiesto la persistencia de este objeto en la obra crítica de Prieto. "Sarmiento. La forja del lector 1839 -1845” (1994), "El alegato. Facundo" (1998), "Las ciento y una. El escritor como mito político" (1988), "Correspondencia de Sarmiento" (prologo inédito de 2001), "Hacia una biografía de Sarmiento" (1953). Prieto asedia la figura de Sarmiento desde diferentes puntos de vista. Rastrea las inquietudes del periodista que al mismo tiempo que elabora una forma y un estilo pone en juego una interpelación a un público futuro que se conformara en y desde ese estilo y esa forma de la escritura. Recorre las estrategias del polemista, que en su enfrentamiento con Alberdi, discute la tensa y siempre problemática relación entre escritura periódica y acción política; definiendo su figuración de escritor como mito político. Todo esto en el contexto de una disputa más amplia relacionada con las definiciones éticas y estéticas de una literatura nacional y las posiciones posibles para el letrado.

La sección siguiente nos presenta al Gaucho y la gauchesca. Los textos "Imagen del gaucho en los viajeros ingleses: 1820 1840" (1992), "La culminación de la poesía gauchesca" (1977), "Prosa y oratoria parlamentaria de José Hernández" (1974) e "Inflexión de lecturas. De Martín Fierro al folletín popular" (1985), le permiten a Adolfo Prieto definir y rastrear las singularidades del género gauchesco desde múltiples planos. Inaugurando un objeto y un punto de vista para la crítica, que 
luego recuperará en el final de su producción cuando destaque la importancia de los viajeros ingleses en el origen de la literatura nacional, Prieto lee cómo aparece en las crónicas argentinas de los viajeros europeos la figura del gaucho. Señala fundamentalmente de qué manera la singularidad de este personaje condiciona una forma particular del relato de viaje en la cual la pulsión utilitaria y descriptiva que lo define se quiebra para dar lugar a un giro romántico en el que el gaucho se vuelve cifra de la tierra, presencia metafísica y poética. A la hora de pensar la trayectoria del género Prieto se detiene en el Martín Fierro para proponerlo como la obra que da nuevo sentido a sus elementos tradicionales complejizando, en la proliferación de niveles constructivos, su naturaleza estética y política. En este sentido, el poema lograría, más allá de ciertas ambigüedades, consumar las intenciones primarias del género como también supondría su clausura. La figura de Hernández se recupera también en su dimensión no ficcional para pensar las continuidades entre su obra periodística y su poema Martín Fierro. Continuidades que resignifican al personaje y a la obra articulando una observación lúcida de la realidad en las complejas circunstancias políticas del proceso de modernización estatal argentino. En los avatares del género, Prieto lee también la dinámica constructiva de los circuitos de lectura y la circulación de bienes simbólicos que constituyen esa matriz cultural que él llamará años después "discurso criollista", dinámica condicionada por la movilidad social y la presencia inmigratoria de fin de siglo. Es la parábola que va de la representación arquetípica de Martín Fierro a la apropiación popular de Juan Moreira a través de la alfabetización masiva y la modernización de la prensa periódica en el nacimiento de los géneros masivos.

Las Multitudes Argentinas presenta dos prólogos breves: "El caso Eduardo Gutiérrez. El populismo. El drama nacional" 
(1967) y "Las multitudes argentinas de José María Ramos Mejía" (1974); en ellos, Prieto analiza las formaciones culturales y las definiciones ideológicas relacionadas con uno de los grandes problemas de fines del siglo XIX y principios del XX: "la cuestión social". En el primero, a partir de la naturaleza seminal de Juan Moreira dentro del proceso de conformación del teatro popular, Prieto estudia el fenómeno de apropiación y las principales características de esa matriz de la cultura popular que se denominó "moreirismo". En el segundo, señala los vaivenes, dudas y torsiones de la incipiente sociología de principios de siglo. Discurso que, desde sus presupuestos positivistas y su voluntad explicativa del nuevo fenómeno de las masas inmigratorias, funcionará como paratexto científico de la literatura naturalista en su carácter de expresión literaria de la xenofobia nacional.

En Literatura de izquierda, vanguardia y criollismo, Prieto se adentra en el estudio de la vanguardia de las primeras décadas del siglo XX. En "Literatura de izquierda. El grupo de Boedo" (1959) indaga las posibilidades de una escritura de izquierda en Argentina, pensando los destiempos y las imposibilidades de la estética realista pietista de Boedo a la hora de sostener la coherencia del posicionamiento ideológico y la capacidad de movilización de las masas hacia la Revolución. "El Martienfierrismo" (1960) recorre lúcidamente las principales característica de la vanguardia martinfierrista: su proceso de importación estética marginal, su potencia renovadora del campo literario y sus relaciones complejas con la tradición. Prieto marca, también, las tensiones entre una ética de la gratuidad para la obra de arte y un mundo en el que se imponían las distintas formas del compromiso político. Finalmente, en su polémica lectura de "Los dos mundos de Adán Buenosayres" (1959), rastrea la evocación satírica que hace Marechal de los personajes y las estéticas de la generación 
(recordemos que la novela fue publicada en 1948). Esta "reconstrucción" generacional, Prieto la interpreta como un regreso en clave cómica de las ideas vanguardistas (principalmente las postulaciones "criollistas" y el vanguardismo literario) pero también como la clausura por vía paródica de esta experiencia.

Íntimamente ligada con la sección anterior Roberto Arlt (nuevamente una "critica de autor") es indagado desde cuatro coordenadas dominantes: la representación de clase, la impronta autobiográfica, la figura del escritor moderno y la torsión estética que pone a su escritura en el lugar de la excepción (inaugurando una crítica arltiana que define la estética del autor en la tensión entre el realismo y el elemento fantástico. Este carácter inaugural debe pensarse, a mi entender, no solo en el contexto de las lecturas que le son contemporáneas, sino también en relación con las genealogías críticas, construidas a partir de la década del 90, que en su voluntad de redefinir la tradición realista ubican la obra de Roberto Arlt en un lugar seminal). "Los siete locos. Los lanzallamas" (prólogo de 1978), "La fantasía y lo fantástico en Roberto Arlt" (1968) y "Silvio Astier, lector de folletines" (1987) son los textos que conforman esta serie. Prieto da un panorama general de la obra arltiana pensando su ubicación pendular en relación con las vanguardias estéticas de la década del 20 (grupos de Florida y de Boedo). A pesar de su voluntad realista, Arlt introduciría una grieta en su representación de lo real, una dimensión imaginaria que pondría de manifiesto el inconformismo de los personajes arltianos que Prieto define como "humillados". Esta tendencia se acentuaría hasta configurar un giro hacia el género fantástico en su escritura posterior. En esta penetración de lo fantástico en la declarada representación realista y en la consecuente construcción de una realidad como simulacro se jugaría la singularidad del 
angustiado "estilo arltiano". Una fantasmagoría que no estaría ajena a los fantasmas personales del autor ni a una tortuosa necesidad de reconocimiento. Finalmente, Prieto rastrea con mucha lucidez, la red de lecturas que se presentan en la obra de Arlt. En los avatares de las inclusiones y exclusiones sobre la que esta red se teje, Adolfo Prieto analiza la naturaleza de una nueva clase lectora y de sus apropiaciones simbólicas. La obra de Arlt, además, señalaría en estas lecturas formativas de sus personajes su propio camino como lector y encontraría la materia para la construcción de un universo imaginario y un estilo que se traduciría en una posición sobre la naturaleza de lo literario.

En la serie siguiente Martínez. Estrada, Prieto propone una indagación en el lenguaje mítico de la narrativa y la ensayística del autor, así como también su proceso de canonización. "Martínez Estrada. El narrador y el lenguaje del mito" (1969), "Radiografía de la Pampa. Configuración de un clásico" (1999), "Muerte y transfiguración de Martin Fierro. Leer desde el 'Epilogo"' (2005) y "Martínez Estrada, el interlocutor posible" (1989) son los ensayos seleccionados para esta sección. Pensando su relación manifiesta con la obra kafkiana, Prieto lee en los cuentos de Martínez Estrada (corpus lateral frente a sus grandes ensayos) la presencia inconsciente y creativa de la explicación mítica de la realidad que de manera razonada dará forma a sus ensayos de interpretación nacional. Ensayos en los que Martínez Estrada, como miembro de una clase cuyas estructuras de vida se ven conmocionadas, asumirá la posición del escritor agonista y profético que desde su yo moral se embarca en una lucha por la dilucidación de los procesos históricos profundos destinada al fracaso. Otro aspecto del cual se ocupa Adolfo Prieto en este recorrido por la obra de Martínez Estrada, es su transformación en un clásico. Un clásico para el futuro que se resignifica en cada coyuntura y en cada acto de lectura. En el cierre de la serie se entabla un 
diálogo posible entre José Luis Romero y el autor de Radiografía de la Pampa. Aquí Prieto vuelve a un postulado que es subyacente también a su obra crítica, la posibilidad de una literaturidad de la historia; es decir, la propuesta del registro literario como expresión de la experiencia histórica colectiva y los procesos profundos que diseñan su dinámica particular.

En la última sección, Los lectores, el público y la crítica y cerrando el plan de la antología, se presentan un grupo de textos donde Prieto se propone una sociología del público y un análisis de la nueva crítica. Los textos seleccionados son: "La literatura argentina y su público" (1958), "La literatura argentina y su público. De antiguas presunciones" (1998), "Los años 60" (1983), "Estructuralismo y después" (1989), "La variante ensayística en la crítica de Rodolfo A. Borello" (2000), "Rama sobre Martí: examen de una estrategia" (1991) y "Encuentros con Ángel Rama. Montevideo, 1967" (1985). Aquí aparecen las reflexiones de Prieto sobre el público real de eso que llamamos literatura argentina. La indagación por la figura del lector supone la postulación complementaria del tipo de autor que se puede construir en este diálogo oblicuo, diferido e imaginario. Lector y autor, junto con los espacios de difusión, consagración y legitimación dibujan el mapa de las posibilidades y las imposibilidades, las ilusiones y las realidades del sistema literario nacional en una coyuntura histórica (la década del 60) de reformulaciones profundas en todos los campos, pero fundamentalmente en el campo cultural. Esta reflexión en torno a un sistema literario conlleva para Prieto una indagación sobre los avatares y reposicionamientos de la "crítica literaria" como disciplina. Así, se presenta en una cartografía posible de la crítica estructuralista y posestructuralista, la tensión entre modernidad y posmodernidad. En esta tensión se juegan básicamente para Prieto, más allá de las limitaciones metodológicas y la felicidad 
de los resultados, la cuestión de la autonomía y el valor de lo literario. El estructuralismo estaría marcado por la aproximación a la obra literaria desde un paradigma "científico" que plantearía la autonomía estructural (el valor específico de lo literario) y la eliminación del contexto. El posestructuralismo borraría las fronteras de los discursos legitimadores de la modernidad, proyectando la crítica literaria en una dimensión semiótica más amplia, multiplicaría las posibilidades ontológicas para lo literario (el valor específico estructuralista se volvería un valor diseminado y cambiante) en un gesto que lo vuelve uno de los discursos de la posmodernidad latinoamericana. Las obras de Rama y Borrello (referentes intelectuales) le permiten a Prieto, en una lectura que se vuelve oblicuamente sobre su propia escritura, rescatar las singularidades del ensayo y la potencia del contexto como dimensiones fundamentales de la escritura crítica.

Conocimiento de la Argentina permite, desde las series o zonas que dibuja, acercarse de un modo integral al trabajo crítico de Adolfo Prieto. Este mapa antológico y conceptual permite ubicar las dominantes de una reflexión que se estructura a sí misma como un diálogo entre textos. Diálogo que a veces dibuja la progresión de una cronología pero que en muchas ocasiones tiene el pulso de una conversación con interrupciones, rememoraciones, digresiones proyectivas y retrospectivas. Toda conversación tiene un tono, un estilo, en Prieto ese estilo es claro, ordenado, exhaustivo pero también súbito, iridiscente. La irrupción de un párrafo, de una oración prepotente hace estallar la vOz crítica consumando su objeto pero también proyectándola hacia una interpelación futura que la actualice y la haga proliferar más allá o más acá de su objeto específico. Quizás ahí, en esa proyección proliferante del sentido resiste la naturaleza íntimamente literaria que él mismo postulaba como esencial en toda experiencia crítica. 